\title{
ADOLESCÊNCIA, SUBJETIVIDADE E QUESTÕES DE GÊNERO NO TEATRO DE MARK RAVENHILL
}

\author{
YOUTH, SUBJECTIVITY AND GENDER IN MARK \\ RAVENHILL'S THEATER
}

Fabiano Fleury de Souza Campos**

\begin{abstract}
Resumo: a partir da análise estrutural, focada, sobretudo, nos personagens da peça Shopping and Fucking (1996), escrita pelo dramaturgo britânico Mark Ravenhill, evidenciamos uma relação incomum entre os elementos formadores desse trabalho teatral e as discussões sobre subjetividade, gênero e sexualidade voltadas para os adolescentes, nos dias atuais. Os contornos dos personagens dessa peça desestabilizam certas noções pré-concebidas sobre a individualidade e a corporeidade, por exemplo. Para a nossa análise, apoiamo-nos sobre os apontamentos de teóricos dedicados tanto ao teatro, como Pierre Sarrazac e Elinor Fuchs, quanto à sociologia e política, como Judith Butler. A peça por meio do discurso agressivo e a violência direcionadas ao corpo dos personagens é capaz de abalar as certezas e a moralidade previamente determinadas de seus espectadores.
\end{abstract}

Palavras-chave: Ravenhill. Teatro contemporâneo inglês. Adolescência. Subjetividade. Gênero.

\begin{abstract}
Shopping and Fucking (1996), written by British playwright Mark Ravenhill, our study shows an unusual relationship between the elements of theatre and the contemporary discussions about subjectivity, gender, and sexuality among adolescents presented in this play. The contours of the characters destabilize certain preconceived notions to individuality and embodiment, for example. Our analysis are supported, for instance, by theater theories developed by Pierre Sarrazac and Elinor Fuchs, and sociology concepts implemented by Judith Butler. Through aggressive discourse and violence directed to the body of the characters, the play is able to shake the certainties and moralities previously found in Ravenhill's viewers. Keywords: Ravenhill. Contemporary British Theater. Adolescence. Subjectivity. Gender.
\end{abstract}

\section{Introdução}

Mark Ravenhill nasceu, em 1966, na cidade de West Sussex e surgiu não apenas como um dos dramaturgos mais provocativos da sua geração, mas também como uma figura central entre os novos escritores do teatro contemporâneo inglês. Estudante de inglês e artes cênicas na Universidade Bristol, mudou-se posteriormente para Londres, onde primeiro trabalhou como assistente administrativo no Teatro Soho Poly e, então, como diretor de workshops entre 1989 e 1991. Em 1993, Mark Ravenhill escreveu sua primeira peça, Close to You, uma comédia sobre um membro do parlamento que tem sua homossexualidade revelada publicamente. E se popularizou por atrair um público jovem e pouco habituado às salas de espetáculo.

Em 2002, Ravenhill foi indicado como diretor artístico do Teatro Nacional da Inglaterra e é atualmente crítico de cultura do jornal londrino The Guardian. De todos os dramaturgos que conquistaram notoriedade com o movimento intitulado In-yer-face, Ravenhill tem, segundo o crítico inglês Aleks Sierz (2000, p. 41), mantido a carreira mais diversificada não só como dramaturgo mas, também, como crítico e ativista das

\footnotetext{
* Mestre em Estudos Linguísticos e Literários em Inglês pela Faculdade de Filosofia, Letras e Ciências Humanas - Universidade de São Paulo e doutorando pela mesma instituição e pelo mesmo programa. Também atua como professor de língua inglesa no ensino fundamental e médio.Email:fabianofscampos@gmail.com
} 
artes cênicas. Até o momento são três volumes publicados contendo, somados, 15 peças produzidas ao longo da sua carreira.

Em janeiro de 2019, estreou no Teatro Royal Court, de Londres, a sua peça mais recente, intitulada Cane, na qual um professor do ensino médio, em vias de se aposentar, vê-se confrontado por antigos alunos que cercam a sua casa e atiram pedras contra a janela.

Em 2000, quando Aleks Sierz descreveu e intitulou o teatro de Mark Ravenhill, Sarah Kane e Anthony Neilson (além do de outros nomes que posteriormente foram surgindo) de In-yer-face, o que lhe chamava a atenção era o modo visceral como esses dramaturgos se aproximavam de suas plateias: "trata-se de um teatro que agarra o espectador pelo pescoço e o chacoalha até que ele entenda a mensagem" (SIERZ, 2000, p. 4) ${ }^{1}$. Essa nova estética era capaz de provocar nos atores e na plateia repostas nãoconvencionais, tocando nos nervos e incomodando bastante.

Frequentemente, essas peças chocam porque empregam estrutura e tons novos ou porque são mais rústicas ou experimentais do que o teatro com que o público está acostumado. Questionando normas morais e sociais, afronta as ideias dominantes relacionadas ao que deveria ou poderia ser mostrado nos palcos; e também trata de sentimentos, confronta tabus, verbalizando o proibido e criando desconforto. Esse teatro parece nos falar sobre quem somos nós.

Diferentemente do tipo de teatro que nos permite sentar e contemplar o que vemos de maneira inocente, o bom teatro In-yer-face (doravante referido como IYF) é aquele que nos conduz a uma viagem emocional extrema, do tipo que nos causa profundo incômodo. O IYF opõe-se a muitas peças que apenas mencionam a violência. A especificidade de $S F$, como é própria do teatro $I Y F$, está na encenação constante de formas variadas da violência: a imoralidade, a inação e o individualismo levado às últimas consequências, por exemplo.

A peça Shopping and Fucking (1996), doravante referida como SF, trata da vida e da subsistência de quatro adolescentes: Lulu, Mark, Robbie e Gary. Brutalizados por uma grande metrópole, na virada do milênio, os personagens vivenciam situações que envolvem sexualidade, uso de drogas, amizade e amor. Ao longo da peça, surge um quinto personagem, mais velho, Brian, que os influencia por meio de uma espécie de relação de poder estabelecida entre ele e os demais. A peça termina em seu ponto de partida, com os personagens Mark, Robbie e Lulu reunidos no apartamento e tentando se alimentar com uma comida insossa feita para ser aquecida em fornos de micro-ondas.

$S F$ foi causa tanto de sucesso quanto polêmica quando estreou no Teatro Royal Court em uma produção realizada pela companhia de teatro britânica Out of joint, na cidade de Londres, no ano de 1996. A comoção causada decorreu também por causa do seu título que, devida à lei inglesa chamada Indecent Advertisement Act, de 1898, passou a se intitular Shopping and $F^{* * * i n g, ~ p e r m a n e c e n d o ~ i n a l t e r a d o ~ n a ~ I n g l a t e r r a ~ a t e ́ ~}$ os dias de hoje. Ironicamente, a censura acabou deixando a peça ainda mais atraente e famosa.

\footnotetext{
${ }^{1}$ Tradução nossa de todas as citações bibliográficas, inclusive da peça $S F$, indicadas nas referências em língua original. A tradução de Laerte Mello (1999), usada na montagem de SF em São Paulo, serviu como fonte de consulta e comparação.
} 


\section{Narrativa, sexualidade e commodity}

Popularizada em diversos países, $S F$ foi interpretada como uma peça sobre adolescentes cuja sexualidade e estilo de vida se destacavam por uma espécie de alienação e desregramento, e que acabou atraindo ao teatro um público identificado como gay e jovem. Quando questionado sobre a peça, o dramaturgo argumentou: "as pessoas gays já tiveram imagens positivas suficientes [de si mesmas]", disse Mark Ravenhill a James Herman (1998) durante uma entrevista para o jornal New York Entertainment que marcava a estreia de $S F$ em Nova York. "O que aqueles afeminados precisam é de algumas imagens negativas capazes de chacoalhá-los [...]”. Ravenhill aparentava defender por meio desse depoimento e da peça $S F$ a existência de um sentimento de alienação condicionado à palavra "gay" e à adolescência, determinados pelos seus significados históricos. Sobretudo, a oposição às políticas públicas voltadas para as identidades sexuais parecia ser uma outra bandeira defendida pelo dramaturgo.

$\mathrm{Na}$ introdução publicada do primeiro volume das peças de Mark Ravenhill, lançada pela editora inglesa Methuen, o crítico Dan Rebellato (2001, p.XV) avalia SF em seu confronto com a teoria pós-moderna defendida por Françoise Lyotard e "a [sua] incredulidade diante das metanarrativas".

Ambientada num contexto fragmentado, $S F$, na interpretação de Rebellato, aceita uma mudança em termos da nossa participação como membros de uma sociedade comum para uma outra em que nos tornamos consumidores ensimesmados de porções de estórias individualizadas. Na cena 4, quando confrontado pela personagem Lulu, o seu companheiro de apartamento, Robbie, defende o seguinte argumento no trecho que, possivelmente, tornou-se o mais conhecido e estudado da obra desse dramaturgo:

Eu acho... Eu acho que tudo que nós precisamos são estórias. [...] Eu acho que tempos atrás tinham grandes estórias. Estórias tão grandes que você podia passar a vida toda só acreditando nelas. A "Poderosa Força das Mãos de Deus e seu Destino". "A Viagem do Esclarecimento". "A Marcha do Socialismo". Mas elas todas morreram, ou o mundo amadureceu ou envelheceu ou se esqueceu delas, e então nós agora estamos inventando nossas próprias estórias. Estorinhas. Cada uma de um jeito. Mas cada um de nós tem a sua. (RAVENHILL, 2000, p. 66) $)^{2}$

Mas a suposição que domina uma sociedade desse tipo em que os consumidores são indivíduos autônomos capazes de tomar decisões racionais são minadas por um destaque atribuído a temas como o desamparo e o vício dos personagens.

A figura, talvez, mais centralizadora da peça, a do personagem Mark, por exemplo, somente pode conceber a própria independência em termos de uma fala de quem recebe conselhos de uma espécie de terapeuta:

Escuta. Quero que você entenda. Eu tenho esse tipo de personalidade, entende? Uma parte de mim é completamente dependente. Eu tenho uma tendência em me definir puramente em termos do meu

\footnotetext{
${ }^{2}$ I didn't say that. I think ... I think we all need stories, we make up stories so that we can get by. And I think a long time ago there were big stories. Stories so big you could live your whole life in them. The Powerful hands of God and Fate. The Journey to Enlightenment. The March of Socialism. But they all died or the world grew up or grew senile or forgot them, so now we 're all making up our own stories. Litlle stories. It comes out in different ways. But we've each got one.
} 
relacionamento com as pessoas. Não consigo me definir estando sozinho $^{3}$ (RAVENHILL, 2000, p.32).

E, em uma cena que ajudou a atribuir à peça "as credenciais de In-yer-face", ele faz a sua oferta de autonomia "dando um beijo grego" ou praticando anilíngua no michê Gary, descrito como um garoto de cerca de catorze anos, ato este que simbolicamente não demanda reciprocidade, mas que, também, por meio do seu fetichismo aparente, expõe a continuidade da dependência retratada como abjeta de Mark aos outros personagens.

O limite até o qual o sexo se tornou uma transação financeira é sugerido no título da peça, e o seu ceticismo diante de qualquer convicção de que a sexualidade é uma força libertadora é condicionado à relação estabelecida entre "comprar" [shopping] e "foder" [fucking] em vez do que, mais especificamente, a qualquer pessimismo de tipo, por exemplo, foucaultiano.

Quando Mark percebe, a sua boca está coberta de sangue, algo que teria decorrido das feridas não cicatrizadas e dos machucados já adquiridos por Gary, durante um ato violento, em que fantasiava ser abusado por uma "figura paterna". Essa fantasia é mais adiante retomada na peça e conta com a participação de Mark, simbolizando o ápice da crescente e cambiante relação, financeiramente mediada, de dependência entre eles.

Mark, no início da peça, ao falar sobre a necessidade de se tornar independente, expõe a superficialidade própria de uma existência que se mercantilizou. Tal discurso, ironicamente, solapa os anseios não só dele mas de todos os personagens que buscam, por meio de suas narrativas, demonstrarem certo grau de autenticidade.

Essas falas revelam uma subjetividade, esvaziada pelo senso comum, e tornaram-se uma marca da escrita e do tipo de personagens criados por Ravenhill ao longo da sua obra. Por isso, o nosso ceticismo em relação a apontamentos, por exemplo, como os do crítico britânico Caridad Svich (2003, p.82) que identifica nas falas "ingênuas" dos personagens evidências de uma sentimentalidade de tipo aburguesada e capaz de reverberar por toda a peça.

Svich cita uma outra fala do personagem Robbie, "foda-se o dinheiro. Foda-se as vendas. Foda-se as compras, e vamos ser... bonitos. Bonitos. E felizes" ${ }^{4}$, como uma prova disso, mas essas declarações são mais um atestado da banalidade e da vagueza das aspirações do personagem, como sugere a elipse de Ravenhill. Robbie está nesse momento recontando a sua experiência enquanto sob o efeito de uma droga conhecida como ecstasy, e descrevendo aqueles sentimentos sintéticos que o levaram a distribuir gratuitamente a substância química que pertencia a Brian (o único adulto da peça), numa festa de música eletrônica, em vez de vendê-la. Como resultado da ação, Robbie acaba levando uma surra e se aprisiona ainda mais ao "sistema" de compras e vendas. E Mark é levado a mutilar Gary em troca de algum trocado. Pois, os três personagens que moram juntos num flat "esvaziado", segundo a rubrica, devem dinheiro ao personagem Brian que, mais velho, faz o papel de um pequeno traficante.

\footnotetext{
${ }^{3}$ Listen. I want you to understand because. I have this personality you see? Part of me that gets addicted. I have a tendency to define myself purely in terms of my relationship to others. I have no definition of myself you see.

${ }^{4}$ Fuck money. Fuck it. This selling. This buying. This system. Fuck the bitching world and let's be .. . Beautiful. And happy' (p.39).
} 
Ao ouvir que ele distribuiu as pílulas, Lulu desiste de cuidar dos hematomas de Robbie, e começa a agredi-lo com xingamentos e tapas a fim de, em seguida, concluir: "homens e mulheres fazem o futuro. Há pessoas lá fora que precisam de mim. Pessoas normais que fazem sexo tipo certinho e quando querem. E os meninos? Os meninos só se fodem" (RAVENHILL, 2000, p.39-40) ${ }^{5}$, arremessando uma garrafa de desinfetante nos olhos do personagem.

A agressão física e verbal, atípica ao padrão de comportamento da personagem Lulu é, como o uso do antisséptico aplicado em Robbie, um meio de utilizar o que está à mão para se defender. Pelas circunstâncias descritas na rubrica do início da cena, em que Lulu masturba Robbie, a postura da personagem também pode ser interpretada como de ciúmes. A expressão dos sentimentos dela funcionam como um clichê que trata a sexualidade gay do personagem, que sente ciúmes de Mark, como algo infantil e descomprometido com o futuro da humanidade.

Lee Edelman (2004) usa o termo "futurismo reprodutivo" a fim de se referir a esse tipo de discurso empregado por Lulu, que também pode ser visto nas falas de outros personagens de Ravenhill, e que torna central a figura "da criança/do filho" para o desenvolvimento de tal argumentação. No entanto, o argumento lacaniano de Edelman sobre essa figura e a sua importância lhe autoriza a falar sem complicações sobre "uma cultura homofóbica" que deve ser recusada por meio de uma identificação com a pulsão de morte, na qual, de certo modo, o futuro inexiste. Por sua vez, Ravenhill direciona a nossa atenção às contradições do posicionamento gay na sociedade contemporânea.

Quando Lulu afirma que "meninos só se fodem", a alusão ao título da peça serve para enfatizar que a sexualidade gay tem se mostrado facilmente mercantilizada e - por razões históricas precisas - sido integrada à lógica da sociedade contemporânea ao mesmo tempo em que essa mesma integração continua a ser uma maneira de banalizála, pois o fetichismo do reino "privado", familiar, contrapõe-se como o loco privilegiado das verdadeiras relações humanas.

Ravenhill é cuidadoso ao minar toda idealização de normalidade familiar ${ }^{6}$ : o sexo domesticado ao qual Lulu recorre - porque, apesar de tudo, ela precisa se sentir querida - oferece-lhe apenas uma segurança frágil; e, nas demais partes da peça, o relacionamento sentimental de Brian com o filho contrasta com o modo como se relaciona com os demais personagens e com o seu papel de pequeno traficante que viabiliza a sua relação parental.

Apesar disso, a interação entre, de um lado, a sexualidade gay e adolescente e, do outro, o tipo de mundo pós-moderno, representado por Ravenhill, ganha força por meio de uma das diversas narrativas ficcionais ou fantasiosas que são recontadas com certas variações ao longo da peça. Na fala do personagem Mark, a ação se emoldura no seu formato derradeiro. Em um mercado pós-apocalíptico, um mutante, do tipo escravo sexual, - uma paródia do corpo gay propagada pelo mercado, com um peitoral perfeito e um pênis enorme - teme a liberdade que Mark, o seu mestre, atribuiu-lhe, crendo que morrerá em virtude disso.

Futurista e distópica - contada de uma maneira que enfatiza um lado cinemático -, a narrativa serve para confirmar uma incapacidade tanto de autonomia quanto de reciprocidade ("estamos no ano três mil e blábláblá", diz o personagem). A peça

\footnotetext{
${ }^{5}$ Boys grow up you know and stop playing with each other's willies.

Men and women make the future. There are people out there who need me. Normal people who have kind tidy sex and [sic] when they want it. And boys? Boys just fuck each other.

${ }^{6}$ São muitos os críticos que observaram entre os personagens Robbie, Mark e Lulu uma espécie de relação familiar. Para mais informações ver, por exemplo, ROBERTS, 2001.
} 
termina como começou, com os personagens dando de comer uns aos outros a comida pré-pronta: a intimidade imatura de Lulu, Mark e Robbie se interagindo com o alimento industrializado.

Os personagens de Ravenhill tendem passivamente a expressar a lógica dos processos sociais e discursos que os "constrói” e que sugere um poderoso funcionamento anti-humanista a serviço da peça. Há uma inquietude nessa constatação, o próprio Ravenhill afirma que não deseja que seu trabalho seja interpretado dessa maneira. Em relação a $S F$, ele defende, por exemplo, que:

Eu sempre escrevi contra o relativismo moral. Eu quero que os espectadores façam escolhas morais: decidindo a todo momento intelectual e emocionalmente - se o que os personagens estão fazendo e decidindo está certo ou errado. Eu acho isso teatral. Isso dá bom teatro...escrever contra os nossos tempos repletos de ironia e despreocupação onde qualquer tipo de hierarquia de valores se esvai, encenar algo que faz as pessoas dizerem, "isso é errado" tem me deixado muito satisfeito... a permissão de dizer, "isso é errado" - sem qualificação - leva-nos um passo mais perto do "isso é certo". E de mudarmos. (RAVENHILL, 2005, p.311)

O problema é que o dramaturgo responde, assim, ao pedido de um espectador que espera condenar as ações dos personagens. Estes, por sua vez, parecem estar presos a uma armadilha, sem opções.

Muita da ironia advinda de Ravenhill serve como meio de lisonjear a plateia e fazê-la se sentir superior aos personagens. Por isso, todo criticismo dirigido ao sistema arrisca a ser neutralizado por despertar um sentimento de desdém contra um tipo de grupo social com características, até certo ponto, identificáveis: os "afeminados", contra os quais as imagens negativas da peça se direcionam.

Quando SF se transferiu para o Teatro Royal Court, em Londres, a peça conquistou uma plateia em larga medida gay, cosmopolita e jovem, mas Ravenhill estava aparentemente consternado por aqueles que "reagiram como se a peça fosse feita para ser "irônica, fria, insensível" (SIERZ, 2000, p.129).

Não é fácil concordar com o dramaturgo quando ele afirma que os espectadores reagiram "erroneamente". Talvez fosse melhor concluir que a estratégia da peça foi inadequada ou, então, concebida para um outro perfil de espectador ou que houve falha da produção. Porém, num outro sentido, a peça é assertiva: homoafetivos ou biafetivos podem estar tão atrelados à lógica do consumismo quanto os heteroafetivos, assim como podem igualmente demonstrar falta de senso histórico, político e social em relação ao mundo em que vivem.

\section{Personagem e subjetividade}

Essa peça de Mark Ravenhill pode ser interpretada como uma exploração dos limites da experiência humana numa fase de transição entre a infância e a vida adulta. A persistência temática sobre a dor, muitas vezes, auto infligida juntamente com o desaparecimento progressivo de marcadores ficcionais das identidades causa-nos a impressão de que a subjetividade e a identidade dos personagens são aspectos centrais da dramaturgia de Ravenhill. As experimentações desse dramaturgo, voltadas para a caracterização dos personagens e a subjetividade, regridem ao passo que o "ser" se torna 
mais presente, ainda que isto ocorra por meio de um processo de desaparecimento simultâneo juntamente com o do personagem. Quais são os laços entre personagem e subjetividade nessa peça?

Nossa definição, portanto, é a de que o "personagem" pode ser qualquer figuração de subjetividade, qualquer contorno teatral de existência humana, independentemente do nível de individuação ou, em sentido contrário, do nível de ausência dos contornos capazes de definir algum ou qualquer traço de individualidade, o que também inclui aquelas entidades que têm recebido nomenclaturas alternativas, como a de "impersonagem", atribuída por Jean Pierre Sarrazac (2012), entre outras.

Essas possíveis terminologias sinalizam um desconforto em definir os personagens como instâncias de linguagem que circunscrevem a reconstrução de biografias imaginárias e estáveis, corpos coerentes e inteligíveis ou personalidades distintas, seguramente localizadas no espaço e no tempo. Esses rótulos são, de fato, importantes como sistemas classificatórios, assim como apontam para questões de suma relevância.

No entanto, a questão essencial por trás da manutenção do termo "personagem" mesmo diante de "figuras" não-individualizadas é a nossa crença no potencial ético e político maior de se expandir a amplitude das experiências humanas encapsuladas por esse termo. Em virtude da relação sinérgica entre o ator, o personagem e o sujeito ${ }^{7}$, uma renegociação do sentido do termo "personagem" pode rearticular o modo como entendemos e apreendemos o termo "sujeito" de maneira menos normativa e exclusivista.

Mais especificamente, a peça $S F$ apresenta a dor física como uma perturbação da unidade, da individualidade e da coerência da personalidade individualizada de tipo liberal-humanista ${ }^{8}$, que, em vez disso, gera uma figuração da subjetividade caracterizada pelo hibridismo e a interconexão. Esse processo dual é articulado por meio da violência extrema contra identidades inteligíveis, corpos e desejos e um profundo respeito pela incompreensibilidade antinormativa resultante dos efeitos oriundos da violência e do amor.

O tema onipresente do ferimento, da dor, em $S F$ marca a pulverização da configuração individualizada do "eu" e a constituição discursiva da subjetividade capaz de ultrapassar a dicotomia entre o eu e o outro. Em relação ao personagem dramático convencional, essas subjetividades melancólicas, híbridas e interconectadas, mesmo que aos trancos, em $S F$ constituem o que poderia ser definida como uma "subversão performativa", seguindo a terminologia de Judith Butler. Em Gender trouble, Butler (2007, p. XXXIV) define as subversões performativas como "práticas paródicas baseadas em uma teoria performativa de gênero capaz de desestabilizar as categorias do corpo, do sexo, do gênero e da sexualidade e resultar numa ressignificação subversiva e propagadora para além do enquadramento binário".

De forma semelhante, as produções de subjetividade em $S F$ empregam personagens convencionais como meios de representação não-convencionais de figuração do "eu". A peça apresenta cinco personagens que são claramente circunscritos por uma teia de afinidade e desejo: Lulu, Robbie e Mark vivem juntos e estão envolvidos entre si emocional e sexualmente; Gary envolve-se aos poucos com Mark e, então, indiretamente com Lulu e Robbie; e Brian, a partir da aproximação "profissional"

\footnotetext{
7 Ver FUCHS, 1996, p.8.

${ }^{8}$ Procuraremos definir esse termo ao longo da análise.
} 
com Lulu, também, aproxima-se dos demais, por um lado, como antagonista: por ser mais velho e por deter algum capital.

Como no caso de um "drama convencional” (SZONDI, 2001, p.8), o diálogo é a força capaz de propagar e renovar o status quo ficcional. Essa interação produz certa polaridade e estabelece relacionamentos entre os personagens investindo-lhes de certos atributos e papeis, como o sadismo de Gary, a ingenuidade de Robbie, o amor incondicional de Lulu, a rebeldia de Mark e o espírito paternal de Brian. Porém, esses personagens convencionais parodiam a figuração liberal-humanista do "eu" ao substituírem certos atributos esperados como unidade, livre arbítrio e autoconsciência por noções como dependência e hibridismo. Mesmo quando negam o desejo de se aproximarem e se envolverem entre si, como transparece a fala inicial de Mark; logo na primeira cena, transparece nos personagens uma necessidade de codependência.

Quanto ao discurso do amor, por outro lado, todos os personagens procuram ser amados por outrem, como se se incorporassem na posição de sujeito, ofertada pelo discurso romântico - e nele reconhecido -, que lhes permite remediar qualquer tipo de instabilidade ontológica. As categorias de reconhecimento ofertadas pelo discurso de amor permitem aos personagens uma identificação e subjetivação que, segundo a terminologia de Butler (2004, p.8), tornam-se "suportáveis", diferentemente das posições oprimidas/abjetas que se lhes impõe pelo discurso da punição, do castigo.

O efeito desses dois discursos é a configuração dos personagens e seus corpos como um lugar fluido e construído por um hibridismo de não-identidade, em vez de lugar estável e totalmente disponível a serem ocupados por sujeitos do tipo liberalhumanista. Em $S F$, a cicatriz, a perplexidade, o ferimento mortal e a genitália incompreensível e "mutante" se tornam simultaneamente os meios e os efeitos da subjetivação discursiva.

Gary recebe a punição por sua culpa alegada de querer ser cuidado por alguém, figura esta descrita por ele como paterna e sádica, quando, ao final da peça, é penetrado por um objeto cortante usado por Robbie, Lulu e Mark, e que, supostamente, leva o garoto à morte. $\mathrm{O}$ encadeamento dessa cena dá-se com a descrição narrativa de um ser mutante, presente na última "estorinha" da peça, contada por Mark, que o constrói a partir de um amálgama de sexualidade, gênero e, de certo modo, identidades psíquicas.

Reforçando uma espécie de círculo vicioso, o corpo do mutante emerge como os efeitos e os meios das forças produtivas do discurso. Assim, conforme Mark afirma que libertará o mutante, ele justifica o discurso e a prática (auto-) punitivos impostos a Gary por seu hibridismo ininteligível de gênero, sexualidade e identidade que, em larga medida, é a condição que autoriza o discurso e a prática dominantes impostos a todos os personagens da peça, exceto a Brian, o personagem mais velho.

A possível morte de Gary ocorre em virtude das suas instabilidades e indefinições. Ainda assim, essa fixidez - a sua contingência - posiciona radicalmente os ideias liberal-humanistas de um ser idêntico, unitário e independente para fora da peça conforme enfatiza o inescapável peso da constituição discursiva do sujeito, da sua intrínseca diversidade e da natureza processual da sua materialidade.

Essa espécie de estupro coletivo sofrido por Gary representa a possibilidade dos efeitos e das condições advindas do poder da subjetivação próprios aos discursos de amor altruísta e castigo totalizante. $S F$ mina a noção cartesiana do corpo como um espaço pré-existente, esvaziado da relação significado/significante e à mercê do agenciamento racional e da vontade do seu próprio dono. Em vez disso, a peça apresenta o corpo como um resultado contingente do processo dinâmico pelo qual 
discursos normativos repetidamente definem e sujeitam as questões relacionadas ao próprio corpo.

A peça enfatiza a estrutura física como o objeto e o efeito do poder mas, acima de tudo, sugere a impossibilidade de os personagens serem eles mesmos sem a existência de Gary e do enfrentamento desse personagem contra si mesmo e os demais personagens. A peça, no final, volta ao seu ponto de partida, recomeçando do zero e sugerindo o movimento em falso.

Em um movimento anticartesiano que uma vez mais acolhe a perspectiva proposta por Butler, a figuração da subjetividade de Gary, assim como dos demais personagens, desestabiliza o cogito como o centro da individualidade suprema, independente $\mathrm{e}$ autossuficiente porque reposiciona o corpo normativamente materializado como o elemento crucial daquilo que o sujeito é. Desse modo, o trabalho de Ravenhill destaca a ontologia humana definida pela carne, o corpo, gerando dúvidas, por exemplo, sobre a percepção de que o centro das micronarrativas ou "estorinhas" pudesse ter origem na "alma" dos personagens, tomados de um sentimento "lírico", como eles mesmos fazem parecer.

SF também sugere que a "subjetivação" costuma falhar na produção de identidades. Mais especificamente, a complexidade física, psíquica e discursiva dos objetos de sujeição/subjetivação, na peça, sempre excede os limites do discurso. Em vez de expressar "sentimentos banais" dos personagens, a dramaturgia de Ravenhill é um testamento tanto à diversidade que habita o centro do ser quanto à inverosimilhança de identidades estáveis. Disso resulta, segundo a mesma autora, uma natureza melancólica do gênero e da sexualidade dos seres.

Em suas reflexões, Butler (1993, p.135) conclui que o uso das posições de gênero sempre depende de um desejo proibido que só pode ser liberado por meio de uma incorporação melancólica. Como resultado dessa instalação necessária do outro na psique, o sujeito nunca é capaz de atingir uma individualidade ${ }^{9}$. Por isso, em $S F$, subjetividade é sinônimo de alteridade e não de particularidade ou autenticidade como o pensamento liberal-humanista defende.

No geral, enquanto $S F$ mantém os personagens de tipos convencionais, individualizados, essa categoria é empregada a fim de desestabilizar e desfigurar a representação ontológica esperada de um ser humano como sendo único, totalmente identificável consigo mesmo e agente de suas ações.

A atuação subversiva acordada entre os quatro personagens mais jovens em oposição à de Brian resultam no entendimento da subjetividade como algo híbrido, mutável, contingente e produzido discursivamente - algo que, se não substitui, ao menos compete com o modo e os contornos de um ser proposto pelo liberalhumanismo.

\section{Referências}

BUTLER, J. Bodies That Matter: On the Discursive Limits of "Sex." London: Routledge, 1993.

Gender Trouble: Feminism and the Subversion of Identity. 1990. London:

Routledge, 2007.

${ }^{9}$ BUTLER, 2004, p.133. 
. Precarious Life: The Powers of Mourning and Violence. London: Verso, 2004.

HERMAN, J. New York Entertainment. January 26, 1998. Disponível em http://nymag.com/nymetro/arts/features/2160/

HARVEY, D. The condition of postmodernity: An enquiry into the origins of cultural change. Malden, MA: Blackwell, 1990.

RAVENHILL, M. Plays 1: Shopping and Fucking; Faust; Handbag; Some Explicit Polaroids. Londres: Methuen Drama, 2001.

. A Tear in the Fabric: The James Bulgur Murder and New Theatre Writing in the Nineties. Theatre Forum 26: 85-92, 2005.

REBELLATO, D. Introduction. In: RAVENHILL, M. Plays 1. London: Methuen drama, 2001.

ROBERTS, R. Gendered media rivalry: Television and film on the London stage. Text and Performance Quarterly, 21, 2, 114-127, 2001.

SARRAZAC, J. Léxico do drama moderno e contemporâneo. São Paulo: Cosacnaif, 2012.

SVICH, C. Commerce and Morality in the Theatre of Mark Ravenhill. In: Contemporary Theatre Review, 13, 1, 81-95, 2003.

SZONDI, P. Teoria do drama moderno. Tradução de Luiz Sérgio Repa. São Paulo: Cosacnaif, 2001.

SIERZ, A. In-Yer-Face Theatre: British Drama Today. London: Faber and Faber, 2000.

Recebido em 29 de maio de 2019

Aceito em 05 de agosto de 2019 